\title{
Enabling Technologies for Medium Area Additive Manufacturing (MAAM)
}
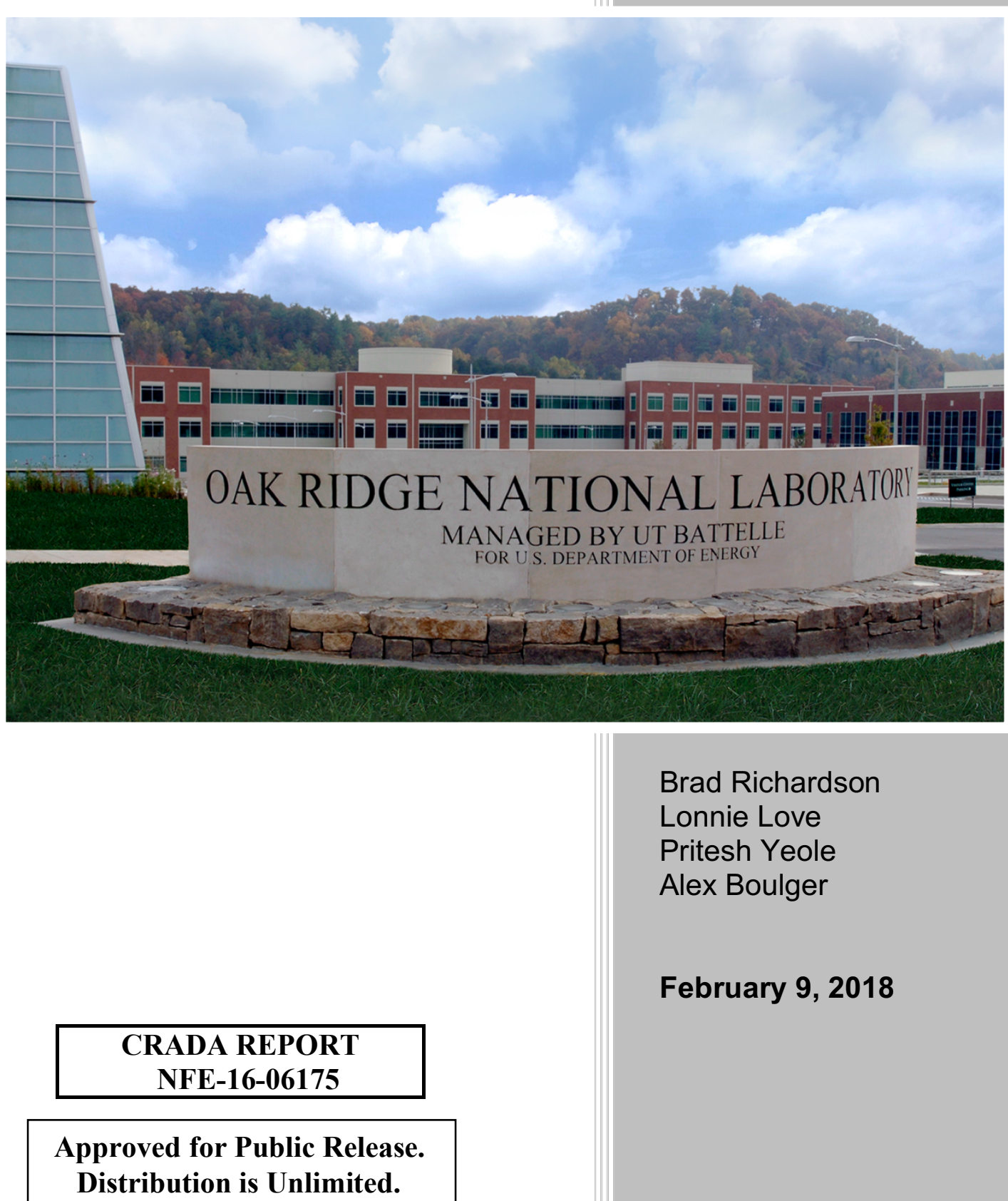

Brad Richardson Lonnie Love

Pritesh Yeole Alex Boulger

February 9, 2018 


\title{
DOCUMENT AVAILABILITY
}

Reports produced after January 1, 1996, are generally available free via US Department of Energy (DOE) SciTech Connect.

Website http://www.osti.gov/scitech/

Reports produced before January 1, 1996, may be purchased by members of the public from the following source:

\author{
National Technical Information Service \\ 5285 Port Royal Road \\ Springfield, VA 22161 \\ Telephone 703-605-6000 (1-800-553-6847) \\ TDD 703-487-4639 \\ Fax 703-605-6900 \\ E-mail info@ntis.gov \\ Website http://www.ntis.gov/help/ordermethods.aspx
}

Reports are available to DOE employees, DOE contractors, Energy Technology Data Exchange representatives, and International Nuclear Information System representatives from the following source:

Office of Scientific and Technical Information

PO Box 62

Oak Ridge, TN 37831

Telephone 865-576-8401

Fax 865-576-5728

E-mail reports@osti.gov

Website http://www.osti.gov/contact.htm|

This report was prepared as an account of work sponsored by an agency of the United States Government. Neither the United States Government nor any agency thereof, nor any of their employees, makes any warranty, express or implied, or assumes any legal liability or responsibility for the accuracy, completeness, or usefulness of any information, apparatus, product, or process disclosed, or represents that its use would not infringe privately owned rights. Reference herein to any specific commercial product, process, or service by trade name, trademark, manufacturer, or otherwise, does not necessarily constitute or imply its endorsement, recommendation, or favoring by the United States Government or any agency thereof. The views and opinions of authors expressed herein do not necessarily state or reflect those of the United States Government or any agency thereof. 
Energy \& Transportation Science Division Advanced Manufacturing Office

\title{
Enabling Technologies for Medium Area Additive Manufacturing (MAAM)
}

\author{
Authors \\ Brad Richardson \\ Lonnie Love \\ Pritesh Yeole \\ Alex Boulger
}

Date Published:

February 9, 2018

\author{
Prepared by \\ OAK RIDGE NATIONAL LABORATORY \\ Oak Ridge, Tennessee 37831-6283 \\ managed by \\ UT-BATTELLE, LLC \\ for the \\ US DEPARTMENT OF ENERGY \\ under contract DE-AC05-00OR22725
}

Approved For Public Release 


\section{CONTENTS}

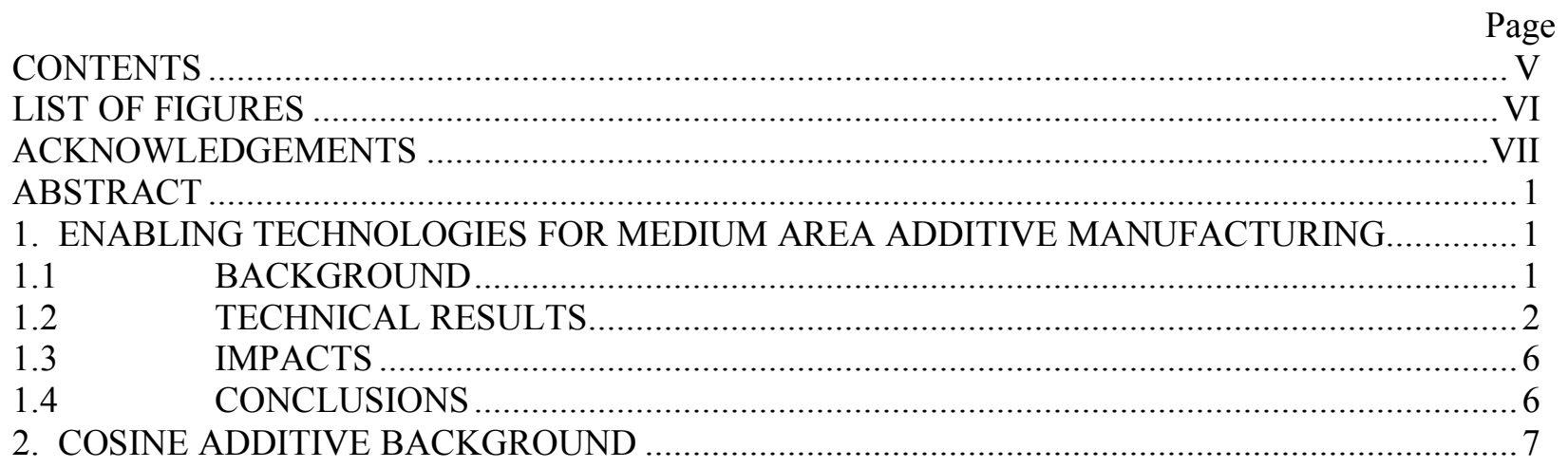




\section{LIST OF FIGURES}

Fig. 1. Cosine Model AM1 Printer. ........................................................................... 2

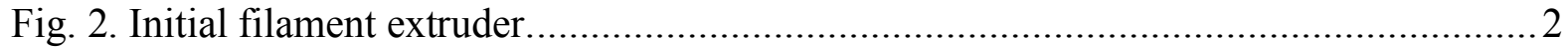

Fig. 3. Initial pellet extruder and sample air foil printed with extruder.............................. 3

Fig. 4. Cosine pellet fed extruder and sample hexagon printed with extruder...................... 3

Fig. 5. Sample mold printed out of ABS with pellet extruder...................................... 4

Fig. 6. Sample ABS $/ 20 \%$ CF hexagon for material testing. ......................................... 4

Fig. 7 Extrusion Rates vs Nozzle Size ....................................................................... 5 


\section{ACKNOWLEDGEMENTS}

This CRADA NFE-16-06175 was conducted as a Technical Collaboration project within the Oak Ridge National Laboratory (ORNL) Manufacturing Demonstration Facility (MDF) sponsored by the US Department of Energy Advanced Manufacturing Office (CPS Agreement Number 24761).

Opportunities for MDF technical collaborations are listed in the announcement "Manufacturing Demonstration Facility Technology Collaborations for US Manufacturers in Advanced

Manufacturing and Materials Technologies" posted at http://web.ornl.gov/sci/manufacturing/docs/FBO-ORNL-MDF-2013-2.pdf. The goal of technical collaborations is to engage industry partners to participate in short-term, collaborative projects within the Manufacturing Demonstration Facility (MDF) to assess applicability and of new energy efficient manufacturing technologies. Research sponsored by the U.S. Department of Energy, Office of Energy Efficiency and Renewable Energy, Advanced Manufacturing Office, under contract DE-AC0500OR22725 with UT-Battelle, LLC. 


\begin{abstract}
ORNL worked with Cosine Additive, Inc. (Cosine) on the design of Medium Area Additive Manufacturing (MAAM) extrusion components. The objective of this technical collaboration was to improve the print speed and part quality of additive manufacturing equipment manufactured by Cosine. A pellet extruder was integrated into the Cosine MAAM printer replacing a filament feed system. Print speed was increased by a factor of ten, and printing with lower cost materials was enabled. In addition, ORNL and Cosine Additive have worked on alternative designs for a pellet drying and feed system.
\end{abstract}

\title{
1. ENABLING TECHNOLOGIES FOR MEDIUM AREA ADDITIVE MANUFACTURING (MAAM)
}

This phase 1 technical collaboration project (MDF-TC-2016-091) was begun on March, 302016 and was completed on November 30, 2017. The collaboration partner Cosine Additive, Inc. is a small business. The extruder on the Cosine Additive AM1 system was changed from a filament fed system to a pellet fed system, and the print speed increased by more than a factor of 10 .

\subsection{BACKGROUND}

Conventional additive manufacturing has been limited in size (under 1 cubic foot build volumes), speed (approximately 1 cubic inch per hour deposition rates) and cost (over \$200/lb feedstock). To address these issues, ORNL developed the Big Area Additive Manufacturing (BAAM) technology. BAAM has radically changed the Additive Manufacturing (AM) industry by increasing the build volume (approaching 1000 cubic ft), increasing the deposition rate $(\sim 1000 \mathrm{cubic}$ inch $/ \mathrm{hr}$ or $40 \mathrm{lb} / \mathrm{hr})$ and decreasing material cost $(\sim \$ 4 / \mathrm{lb})$. This paradigm shift has opened up many new applications of the technology. However, there is a market space that is currently not being developed despite tremendous interest. Medium Area Additive Manufacturing (MAAM) spans the space between the conventional AM technologies (cubic foot build volume) and the BAAM (in excess of 250 cubic foot build volume). Specific markets include appliances, automotive and aerospace interior (seats, consoles, ducting), tooling and consumer electronics.

Cosine Additive, Inc. (Cosine), a small startup company, is commercializing a new fused deposition modeling system that starts to bridge this gap between conventional systems and BAAM. Cosine's current platform has a 43" x 33" x 35" build volume. The initial filament fed system, as delivered to ORNL, had a peak deposition rate of $3.5 \mathrm{~kg}$ in 24 hours (approximately 10 cubic inches per hour). This deposition rate is near the theoretical limit of conventional filament fed polymer systems. Higher production rates are required for the Cosine system to be competitive with low to medium volume manufacturing technologies. The development of powder and pellet fed extrusion technologies can overcome these barriers and enable significantly higher deposition rates.

Prior work at ORNL has shown that, for a given flow rate there is a preferred part size range. If the part is too small, it builds up too much heat and distorts. If the part is too large, it gets too cool and cracks. For a 36 " x 36 " solid cross sectional area with a 0.050 " layer height, the target flow rate is approximately 200 cubic inches per hour or approximately $7.5 \mathrm{lbs} / \mathrm{hr}$. This served as the target deposition rate for the proposed MAAM system. 


\subsection{TECHNICAL RESULTS}

ORNL's original Cosine AM1 Printer (Fig. 1 and 2) was outfitted with a filament extruder. After initial testing of the machine, a pellet based extruder from DPP Technologies was procured for the printer. Cosine provided integration of the extruder onto the printer and into the printer control system.

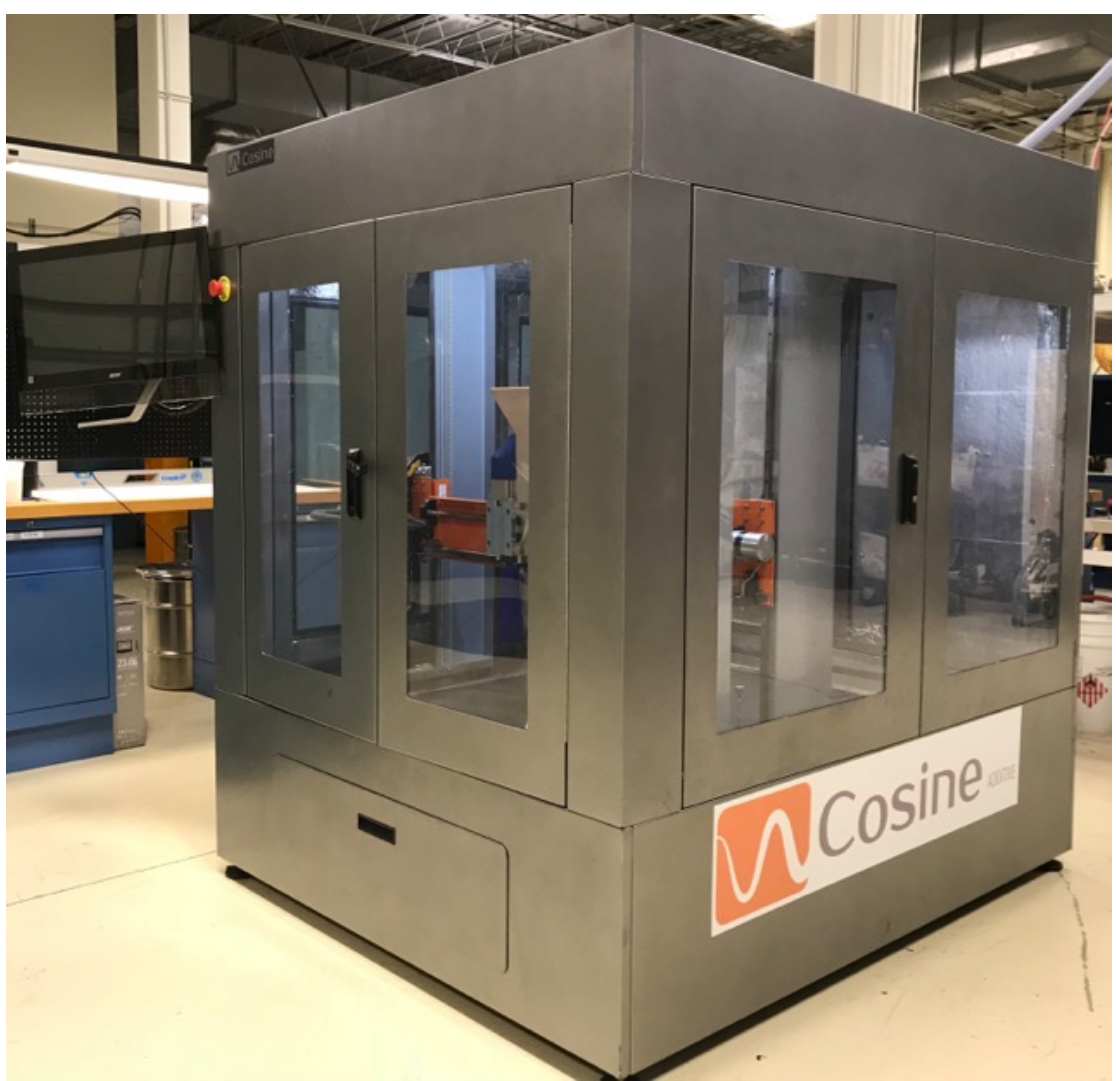

Fig. 1. Cosine Model AM1 Printer.

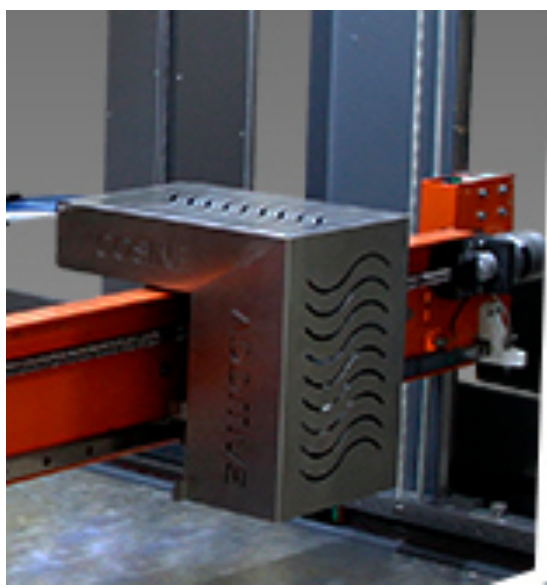

Fig. 2. Initial filament extruder. 
The pellet extruder and an initial part are shown in Fig. 3. The DPP extruder deviated from a traditional extruder in that it used a modified boring bit and was limited in the pressure that it could generate. After a number of tests, it was determined that the DPP pellet extruder was insufficient for Cosine machine applications.
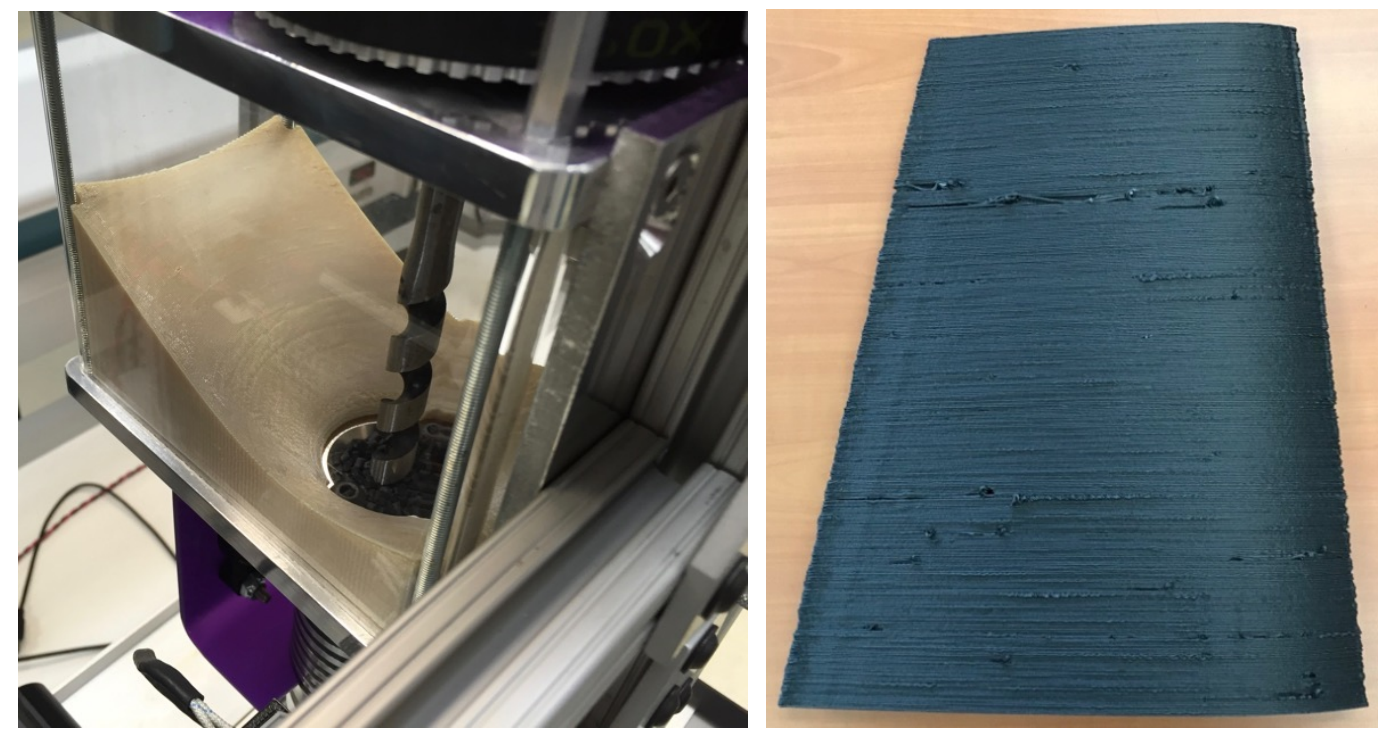

Fig. 3. Initial pellet extruder and sample air foil printed with extruder.

Cosine developed an extruder to replace the DPP extruder. The Cosine extruder (Fig. 4) is currently mounted on ORNL's AM1 printer. ORNL printed parts from both Acrylonitrile Butadiene Styrene (ABS) / 20\% Carbon Fiber (CF) and Polyphenylene Sulfide (PPS) / 50\% Carbon Fiber. Shown in Figure 4 is a test piece printed out of PPS. A sample mold is shown in Fig. 5 and a hexagon for material testing in Fig. 6. Both of these parts are printed from ABS / 20\% Carbon Fiber.
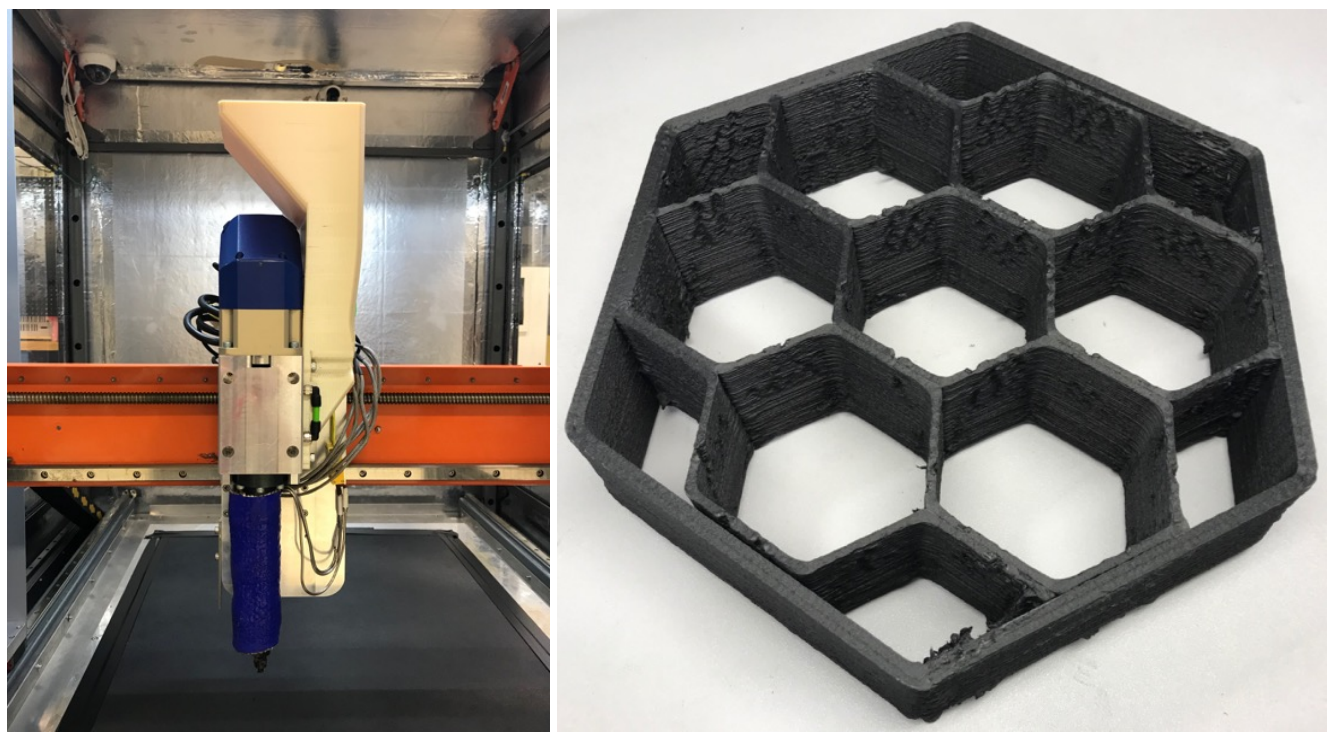

Fig. 4. Cosine pellet fed extruder and sample hexagon printed with extruder. 


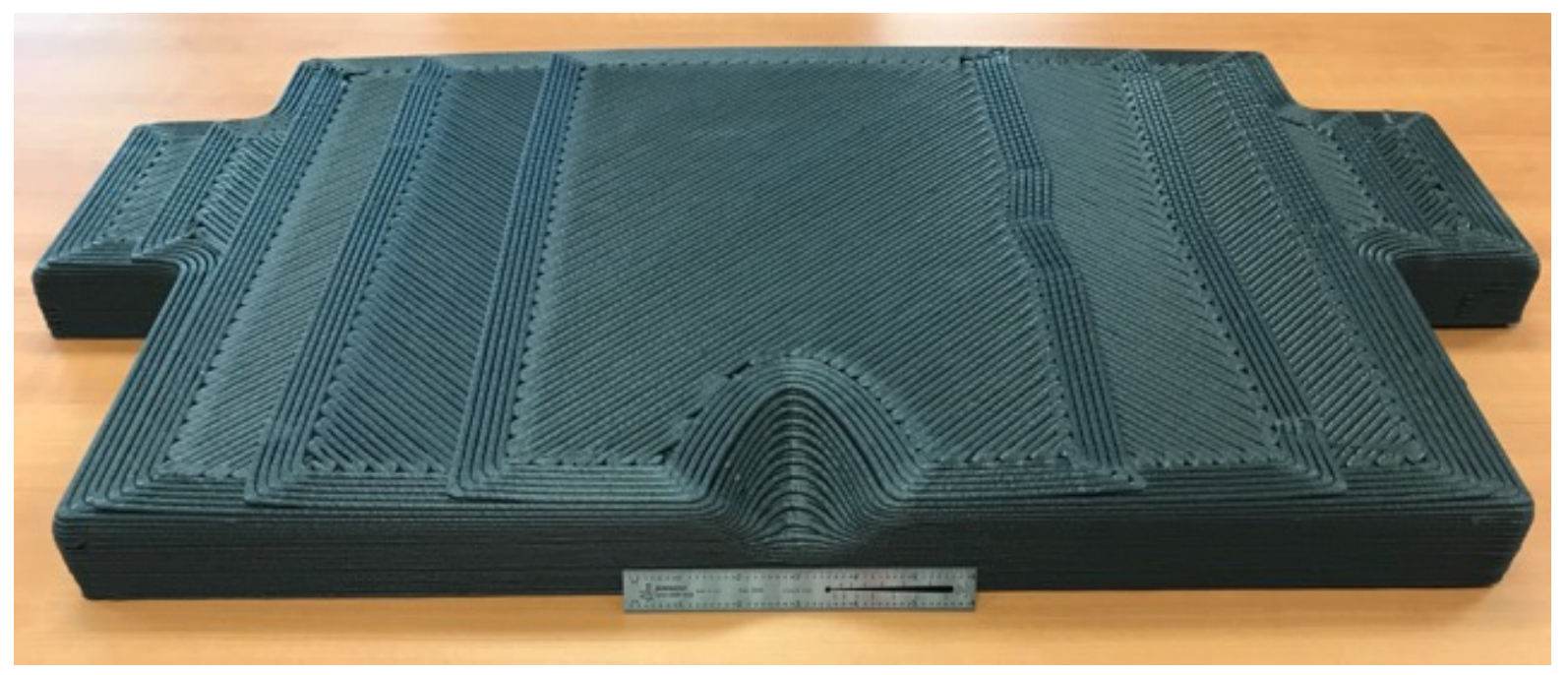

Fig. 5. Sample mold printed out of ABS with pellet extruder.

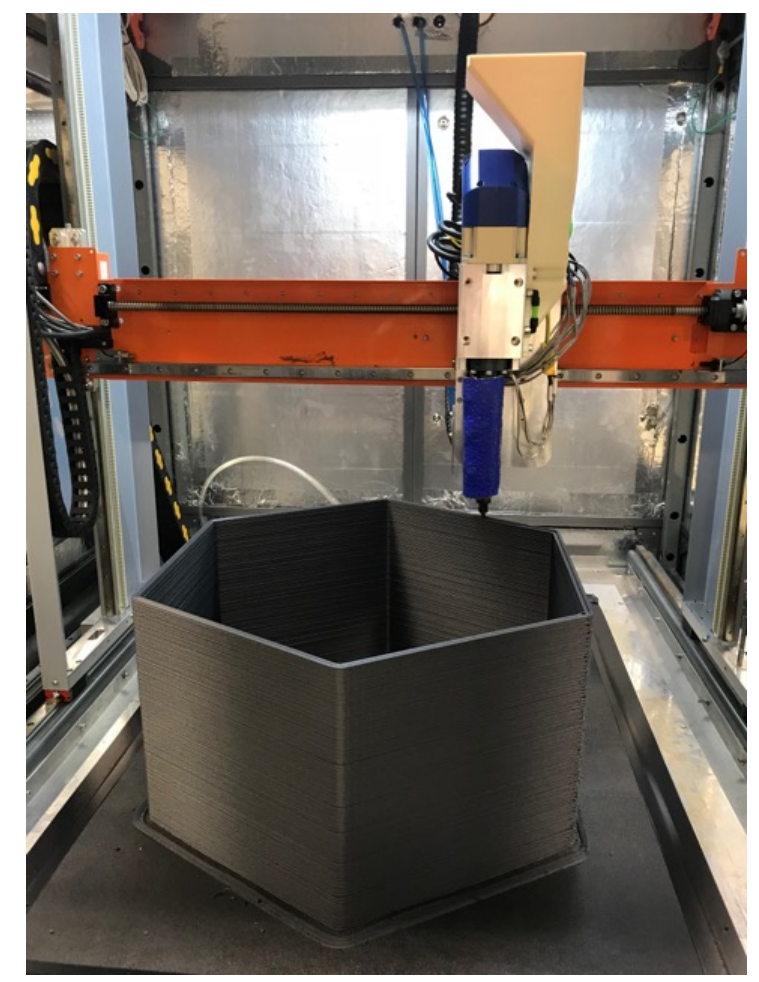

Fig. 6. Sample ABS 20\% CF hexagon for material testing.

The hexagon shown in Fig. 6 was used to test material properties for comparison to properties obtained from a sample printed on the BAAM. Table 1 shows the properties and comparison to the properties obtained from the BAAM printed test piece. A $3.25 \mathrm{~mm}$ nozzle was used for printing the Cosine hexagon. In general, results were within $10 \%$ with a couple of exceptions. 
Table 1 Comparison of Material Properties

BAAM and Cosine - ABS 20\% CF

\begin{tabular}{|c|c|c|c|c|c|}
\hline \multirow{2}{*}{ Property } & \multicolumn{2}{|c|}{ BAAM } & \multicolumn{2}{|c|}{ Cosine } & \multirow{2}{*}{$\begin{array}{c}\text { \% Difference } \\
\text { Avg }\end{array}$} \\
\hline & Avg & Std Dev & Avg & Std Dev & \\
\hline Tensile - X (MPa) & 73.7 & 0.9 & 73.6 & 0.8 & $-0.1 \%$ \\
\hline Tensile Modulus (GPa) & 12.3 & 0.1 & 10.5 & 0.1 & $-14.7 \%$ \\
\hline Tensile - Z (MPa) & 16.4 & 1.7 & 18.0 & 2.3 & $10.0 \%$ \\
\hline Tensile Modulus (GPa) & 2.8 & 0.04 & 2.6 & 0.1 & $-6.9 \%$ \\
\hline Flexure - X (MPa) & 94.1 & 7.3 & 100.0 & 0.1 & $6.3 \%$ \\
\hline Flexure Modulus (GPa) & 10.1 & 0.1 & 10.0 & 0.2 & $-1.1 \%$ \\
\hline Flexure - Z (MPa) & 29.0 & 0.7 & 36.5 & 0.9 & $25.9 \%$ \\
\hline Flexure Modulus (GPa) & 2.8 & 0.1 & 2.9 & 0.1 & $2.5 \%$ \\
\hline Interlaminar Shear Strength - X (MPa) & 11.9 & 0.4 & 12.3 & 0.2 & $4.1 \%$ \\
\hline Interlaminar Shear Strength - Z (MPa) & 4.3 & 0.1 & 4.9 & 0.4 & $15.0 \%$ \\
\hline 5 Samples for each & & & & & \\
\hline
\end{tabular}

A series of nozzles were fabricated with sizes varying from $0.5 \mathrm{~mm}$ to $4.0 \mathrm{~mm}$. The nozzles consist of a compression fitting and $1 / 4$ inch pin stock with a hole drilled to the appropriate diameter. Extrusion rates for ABS $20 \% \mathrm{CF}$ were measured for each nozzle at multiple extruder motor speeds as shown below in Fig. 7. The motor has a maximum rated operating speed of 3,000 rpms. Table 2 shows the values for the extrusion rate values in $\mathrm{kg} / \mathrm{hr}, \mathrm{lb} / \mathrm{hr}$ and $\mathrm{in}^{3} / \mathrm{hr}$. As can be seen from the table, that with the $4 \mathrm{~mm}$ nozzle, the extruder rate is capable of exceeding the target extrusion rate of $200 \mathrm{in}^{3} / \mathrm{hr}$.

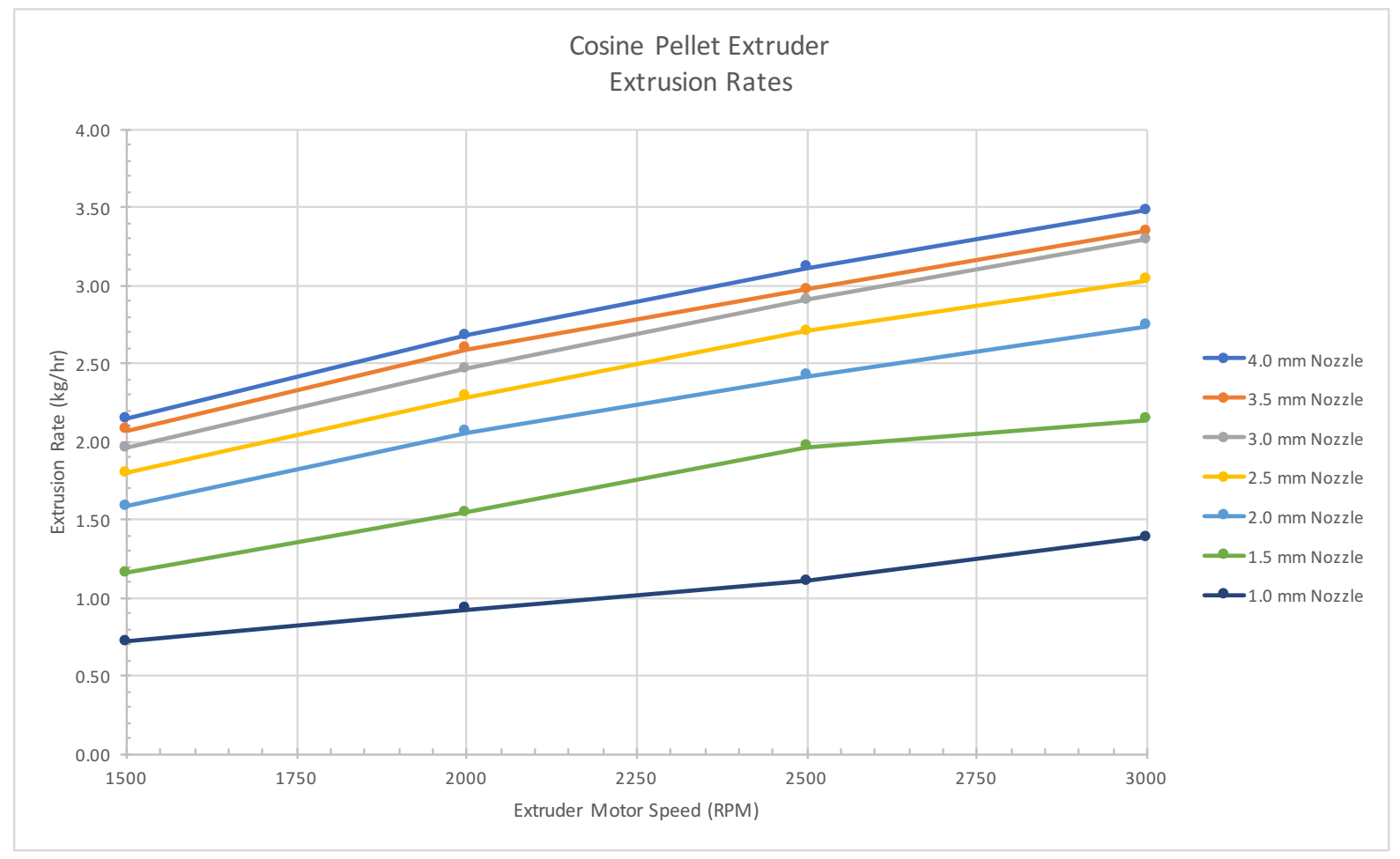

Fig. 7 Extrusion Rates vs Nozzle Size for ABS $20 \%$ CF 
Table 2 Extrusion Rate Values at 3,000 RPM for ABS 20\% CF

\begin{tabular}{|c|c|c|c|}
\hline Nozzle & $\mathrm{kg} / \mathrm{hr}$ & $\mathrm{lb} / \mathrm{hr}$ & $\mathrm{ci} / \mathrm{hr}$ \\
\hline $4.0 \mathrm{~mm}$ & 3.48 & 7.67 & 186.1 \\
\hline $3.5 \mathrm{~mm}$ & 3.35 & 7.38 & 179.2 \\
\hline $3.0 \mathrm{~mm}$ & 3.29 & 7.26 & 176.2 \\
\hline $2.5 \mathrm{~mm}$ & 3.03 & 6.68 & 162.2 \\
\hline $2.0 \mathrm{~mm}$ & 2.74 & 6.03 & 146.4 \\
\hline $1.5 \mathrm{~mm}$ & 2.14 & 4.71 & 114.4 \\
\hline $1.0 \mathrm{~mm}$ & 1.38 & 3.05 & 74.0 \\
\hline
\end{tabular}

Use of pellets versus filament results in a significant reduction in material cost. For example, plain ABS filament (with no carbon fiber or glass) can be obtained for as low as $\$ 10 / \mathrm{lb}$ from Amazon. 3DXTech sells ABS filament with $15 \% \mathrm{CF}$ for $\$ 34 / \mathrm{lb}$. Our most recent bulk procurement of ABS $20 \%$ CF pellets cost $\$ 5.20 / 1 \mathrm{~b}$. Less expensive material, coupled with an automated pellet feed system makes for a practical and cost effective system.

Now that the machine is outfitted with a working pellet based extruder, the next steps are to adapt ORNL's Slicer for use with the AM1, to design a tamper for integration into the system and to incorporate a pellet dryer and feed system. These improvements are envisioned to be a part of Phase 2 of this technical collaboration.

\subsection{IMPACTS}

The development of MAAM will open up new manufacturing opportunities in medium scale systems that can impact appliance manufacturing, energy, buildings and transportation. There is no technology on the market like this today, and Cosine Additive is the world leader manufacturing systems of this size and magnitude. Success will enable the development of an additive manufacturing system that can open new markets for rapid manufacturing. Examples include:

- Prototype appliances- The size and speed of the MAAM will enable rapid prototyping of future appliances increasing efficiency and innovation.

- Low to medium volume manufacturing - MAAM will enable low to medium volume production of medium sized articles impacting a broad spectrum of industries such as housing, consumer electronics, automotive and aerospace.

- Medium sized tooling - MAAM will enable the rapid manufacture of medium sized tooling at a rate and size that is greater than the state of the art with greater detail than current BAAM technology.

\subsection{CONCLUSIONS}

Conversion of the Cosine AM1 printer from a filament fed system to a pellet fed system has resulted in a number of improvements in the system. These include increasing extrusion rates by more than an order of magnitude and enabling the use of lower cost pellets and a variety of materials, including carbon fiber reinforced materials.

Phase 2 of this technical collaboration, if approved, will include adapting the ORNL Slicer for 
use with the Cosine AM1, the addition of a tamper mechanism for more consistent layer height in builds, and the addition of a pellet dryer and feed system. Phase 2 will also include testing of the system with a variety of materials for improved CAD to part capability, quality and dimensional accuracy of printed parts and feed rates greater than $10 \mathrm{lbs} /$ hour.

\section{COSINE ADDITIVE BACKGROUND}

Cosine Additive, founded in 2013, has grown rapidly since its inception, gaining respect in the additive community through aggressive technological improvement of the thermoplastic deposition process. Their in-house machining, manufacturing, circuitry, and programming allow incredibly fast iterations of complex robotic solutions. Cosine has been featured by companies such as Solidworks as a case study of successful entrepreneurism in the hardware manufacturing space.

Cosine Additive is on a mission to improve the state of the art in filament based polymer 3D printing. They have a simple premise of increasing the usefulness of the technology to industry professionals. To achieve this, many technical aspects had to be addressed. A fundamental decoupling of hardware, software, and materials had to be achieved so that innovation could continue at an exponentially faster rate.

Excellence through superior hardware and an open-market materials approach is the path that Cosine Additive is taking. Instead of being locked into a few proprietary material choices, their platform places no restrictions on the use of third party thermoplastics. This approach allows collaboration with industry leading polymer firms to develop the next generation of materials for additive manufacturing. By focusing on particular industrial use cases, great value can be had through their innovate system. Applications such as thermoforming, composite layup tooling, composite cores, and high strength jigs are all ideal applications for Cosine's Composite Additive Manufacturing (CAM) process. 